\title{
Safety Health Impacts of Particulate Matter from Excavation Work Sites
}

\author{
Giuseppe Pizzo and Marina Clerico
}

DIATI-Department of Environment, Land and Infrastructure Engineering,

Politecnico di Torino, Corso Duca degli Abruzzi 24, 10129 Torino, Italy

Received 2012-07-05; Revised 2012-07-18; Accepted 2012-07-21

\begin{abstract}
Epidemiological studies have shown a linear relationship between airborne particulates and effects on human health. This study examines the risk that can be run by populations which are exposed to significant pollutant sources such as excavation in urban areas for renovation work. The health risk assessment methodology defined by the WHO air quality guidelines for Europe was applied to assess the possible health effects from exposure to $\mathrm{PM}_{10}$ for daily average concentrations greater than $50 \mu \mathrm{g} \mathrm{m}^{-3}$ and greater than $100 \mu \mathrm{g} \mathrm{m}^{-3}$ for three consecutive days and for increments of $10 \mu \mathrm{g} \mathrm{m}{ }^{-3}$. The methodology adopted was based on daily average concentrations detected in a monitoring period of 8 months in different areas in and around the excavation work site with concentrations of $\mathrm{PM}_{10}$ below or above the legal limits. The exposure estimates calculated show that urban areas with excavation work sites are damaging to human health, due to the large number of people exposed and the already high concentrations of $\mathrm{PM}_{10}$ within cities. It was found that even when in parts of a work site legal limits of $\mathrm{PM}_{10}$ are not exceeded, adverse effects on health still occur. The application, in the present study, of the WHO methodology of exposure assessment indicates the risk ratio for effects on human health. Epidemiological data do not suggest exposition threshold values below which there are no adverse health effects. It is not possible to identify a $\mathrm{PM}_{10}$ concentration value, attributable to an additional source, such as an excavation work site, below which there is no damage. The purpose of this research is therefore to stimulate debate and decisions by public authorities, in order to deepen knowledge and to address issues related to airborne particulates.
\end{abstract}

Keywords: Particulate Matter, Epidemiology, Safety Health Risk, Excavation Work Sites, Local Government

\section{INTRODUCTION}

The World Health Organization, in the guidelines of 2005 (WHO, 2006), described effects to human health from particulate matter, ozone, nitrose dioxide and sulfur dioxide. Most of the scientific literature (ATS, 2000; Zagar et al., 2005; WHO, 2003) focuses on issues affecting the respiratory and cardio-circulatory attributable in particular to the short and long term exposure.

This type of pollution reduces life expectancy in the countries of Central and Western Europe for Almost A year (EEA, 2007). WHO estimates that each year at least 8,000 people die prematurely due to the long-term effects of particulate matter. By 2020, because of the $\mathrm{PM}_{2,5}$, there is a loss of life expectancy of 5.5 months. Since these calculations were performed without considering the secondary organic particles and are relate to the impacts of a population with average age over 30 years, the total impact is underestimated.
The analysis conducted by researchers (Pope et al., 2002) have demonstrated a reduction in lung function in adults and children and the increased incidence of bronchitis among infants, due to one year exposure to airborne particulates. These effects have been observed to an annual average concentration level of less than 20 $\mu \mathrm{g} \mathrm{m}^{-3}$ for $\mathrm{PM}_{2,5}$ and less than $30 \mu \mathrm{g} \mathrm{m}^{-3}$ for $\mathrm{PM}_{10}$.

Ultrafine particles, $\mathrm{PM}_{0,1}$, have also been the subject of scientific and medical attention. Although the toxicity of these substances is well known, the available epidemiological information and data do not still allow obtaining a precise definition of the relationship exposureresponse. The guidelines do not provide then any recommendation on the concentrations of this substance.

The European population is exposed to air pollution values that exceed the standards set by the European Union and the World Health Organization (WHO) for the outdoor Environment (EEA, 2009). The urban and suburban areas are the most affected ones (Larsen, 2008). 
The average $\mathrm{PM}_{10}$ annual concentration limit of $40 \mu \mathrm{g}$ $\mathrm{m}^{-3}$ imposed by the Italian national legislation, according to European DIRECTIVE 2008/50/EC (2008) on ambient air quality and cleaner air for Europe, is not justified by technical reasons or special medical evidence. Such $\mathrm{PM}_{10}$ limit does not correspond to any WHO guideline limit, neither to other limits imposed in other parts of the world (the United States have repealed for years the annual limit for $\mathrm{PM}_{10}$, retaining only daily limit).

Road transport represents the main $\mathrm{PM}_{10}$ emission source.

The introduction in Europe of engine euro classification, with vehicle replacement from 1993, has resulted in a decrease of emissions $\mathrm{PM}_{10}, \mathrm{PM}_{2,5}$ and nitrose dioxide (CEPMEIP, 2003). Wear of brakes and tires, as well as the resurgence of dust material, represents then a significant source of particulate matter.

The "natural background" contribution to the concentration of the particulate matter is very small compared to the contributions of "regional background" due to anthropogenic emissions produced on a large scale (transboundary contributions) and from neighboring areas within the region in relation to weather conditions that affect the dispersion of pollutants.

The contribution of the "urban background" further increases the levels of the urban areas, but it superficially affects remote areas (Zhang et al., 2011). $\mathrm{PM}_{10}$ concentrations in urban areas most exposed to traffic and affected by a particular propagation conditions, have significant daily and annual averages concentrations. The Air Quality Plans of the DIR 2008/50/EC are aimed at facing the problem.

When the standard emission conditions are associated with a significant additional source, the conditions may become critical: It is what often happens in the excavation work sites in urban area.

This study, through the long-term monitoring of $\mathrm{PM}_{10}$ in an excavation work site in urban area, wants to assess the contribute to $\mathrm{PM}_{10}$ concentrations, comparing and evaluating effects on health of the population.

\section{MATERIALS AND METHODS}

The WHO air quality guidelines provide quantitative estimates of risk for specific health effects. They are based on epidemiological and toxicological analysis. Further studies on health effects considering the Total Suspended Particulate (TSP) as an indicator of exposure have also been developed. They have provided additional details, but they are not suited to derive the relationship between exposure and response for PM, since the TSP includes particles too large to be inhaled. There is therefore a high uncertainty about possible health effects of this size fraction.
Table 1. Correlation Relative risk associated with an increase of $\mathrm{PM}_{10}$ and $\mathrm{PM}_{2,5}$ daily average concentration of 10 $\mu \mathrm{g} \mathrm{m}^{-3}$ for short-term exposure

\begin{tabular}{lll}
\hline Effects & $\begin{array}{l}\text { Relative } \\
\text { risk } \mathrm{PM}_{2,5}\end{array}$ & $\begin{array}{c}\text { Rlative } \\
\text { risk } \mathrm{PM}_{10}\end{array}$ \\
\hline Use of bronchodilator & - & 1,0305 \\
Cough & - & 1,0356 \\
$\begin{array}{l}\text { Wheezing } \\
\text { Changes in peak expiratory }\end{array}$ & - & 1,0324 \\
flow Hospital admissions & & $-0,13 \%$ \\
for respiratory problems & - & 1,0080 \\
Daily mortality & 1,015 & 1,0074 \\
\hline
\end{tabular}

Table 2. Estimated number of people (in a population of one million individuals) who experience health effects over a period of three consecutive days, with a $\mathrm{PM}_{10}$ average daily concentration of 50 and $100 \mu \mathrm{g} \mathrm{m}^{-3}$

No. of people who may
experience health effects due
to $\mathrm{PM}_{10}$ episodes of pollution
for three consecutive days
January- Location: $\mathrm{P} 1$

\begin{tabular}{lcc}
$\begin{array}{l}\text { Indicators of } \\
\text { ehalth status }\end{array}$ & $\begin{array}{l}\text { Average daily } \\
\text { concentration } \\
\text { of } 50 \mu \mathrm{g} \mathrm{m}^{-3}\end{array}$ & $\begin{array}{l}\text { Average daily } \\
\text { concentration } \\
\text { of } 100 \mu \mathrm{g} \mathrm{m}^{-3}\end{array}$ \\
\hline $\begin{array}{l}\text { Number of deaths } \\
\begin{array}{l}\text { Number of hospitalizations } \\
\text { for respiratory problems }\end{array}\end{array}$ & 4 & 8 \\
$\begin{array}{l}\text { Use of bronchodilator } \\
\begin{array}{l}\text { Symptoms of } \\
\text { respiratory irritation }\end{array}\end{array}$ & 4863 & 6 \\
\hline
\end{tabular}

The measures from fixed sites provide regular and accurate information on the concentration of pollutants in the atmosphere, but do not necessarily reflect the local conditions of immission and exposure of individuals in different environmental conditions. Such measures consider that all individuals in a specific area are subjected to the same exposure. In this way the spatial variability within the same area and the differences between people who live outdoors is not taken into account.

The WHO guide values for $\mathrm{PM}_{2,5}$ and $\mathrm{PM}_{10}$ are useful to evaluate the effects of exposure to long-term and the short term. The annual average guide value for $\mathrm{PM}_{2}$, 5, for long-term exposure, is $10 \mathrm{ug} \mathrm{m}^{-3}$. It was chosen to represent the minimum value of an interval, after which significant effects on health occur.

This parameter was defined basing on evaluations of epidemiological studies for long-term exposure, which estimated the relationship between exposure and mortality. An average $\mathrm{PM}_{2,5}$ concentration of $10 \mathrm{~g} \mathrm{~m}^{-3}$ is lower than literature values, where cases of mortality are found. For example, in a study conducted by the ACS (American Cancer Society) the lowest $\mathrm{PM}_{2,5}$ concentration values causing mortality are between 11 and $15 \mathrm{ug} \mathrm{m}^{-3}$. 
The $\mathrm{PM}_{10}$ guide value was instead obtained by using the WHO relation saying that the $\mathrm{PM}_{10}$ guide value is double than $\mathrm{PM}_{2,5}$, thus indicating the WHO annual average for $\mathrm{PM}_{10}$ in $20 \mathrm{ug} \mathrm{m}^{-3}$.

The WHO has estimated the relative risk (Table 1) for different effects associated with an increase of $\mathrm{PM}_{10}$ and $\mathrm{PM}_{2,5}$ daily average concentration of $10 \mu \mathrm{g} \mathrm{m}^{-3}$. Such effects arise from a temporal distance less than a day to 2-3 days.

It is not known the real long term life reduction expectancy associated with increased daily mortality for short term exposure.

WHO estimates (Table 2) the health effects for $\mathrm{PM}_{10}$ air pollution episodes lasting three consecutive days with daily average concentrations of 50 and $100 \mu \mathrm{g} \mathrm{m}^{-3}$, for a population of one million people.

WHO has also estimated the risk and health effects of long-term exposure to PM. In this case the available data are less than those relating to the short-term effects. The relative risk for mortality due to a $10 \mu \mathrm{g} \mathrm{m}^{-3}$ increase in long-term exposure to $\mathrm{PM}_{10}$ is equal to 1.10 , while the same increase of $\mathrm{PM}_{2,5}$ is 1.14 (Dockery et al., 1993). A second epidemiological study estimated a relative risk for mortality due to an increase of $10 \mu \mathrm{g} \mathrm{m}^{-3}$ for $\mathrm{PM}_{2,5}$ equal to 1.07 (Pope et al., 1995). It was also estimated the relative risk for bronchitis as a result of the analysis performed on children of North America (Dockery et al., 1996). It is equal to 1.34 and 1.29 for long-term increase of $10 \mu \mathrm{g} \mathrm{m}^{-3}$ for $\mathrm{PM}_{2,5}$ and $\mathrm{PM}_{10}$, respectively. In the present study a long-term monitoring data (Pizzo and Clerico, 2011) in an excavation work site in urban area have been used, in order to quantify the relative risk resulting from exposure to $\mathrm{PM}_{10}$ for three consecutive days.

\subsection{Case Study}

The case study concerns the analysis of effects on population of particulate matter generated by a large excavation work site in an urban area.

- The site is part of an important project to transform the city

- The interventions provided within the site, which represent a source of dust, are divided into the following processes

- Demolition of the buried artifacts structures and foundations of existing industrial sites

- Crushing and screening of debris from demolition in mobile plant for the recovery of non-hazardous waste, installed within the site area. This material is deposited in specific areas waiting for the re-use within the site or marketed outside

- Excavations for infrastructure works and private construction. The material is loaded onto trucks and delivered to the screening plant located within the area. The undersize fraction is deposited in the appropriate areas in heaps of $1000 \mathrm{~m}^{3}$. This material is dampened (by watering) or covered with protective HDPE sheeting to prevent dispersion of dust into the atmosphere

- Backfill material from undersize, by grab excavators, loaders and graders

The typical sources of dust emission in the excavation work sites are:

- Tracks yard and storage areas

- Areas of material handling

- The resurgence by wind

Another important emission, unless properly controlled, is the transportation of materials on public roads; because of the dispersion of the load and the release of the means of transport not enough cleaned (tires, boxes).

It's also necessary to evaluate the contribution from road traffic emissions to be added to the site. The dispersion of dust into the air then depends on the weather.

The methodology of health risk assessment of WHO to develop estimates of damage in the excavation work sites has been used for two different scenarios:

- Scenario $\mathrm{A} \rightarrow$ excavation work sites in urban area

- Scenario B $\rightarrow$ excavation work sites in urban peripheral area (outside of the metropolis, but within the urban area)

The estimates of adverse health effects are calculated on average values of daily $\mathrm{PM}_{10}$ concentration, detected in monitoring activities in different sites. Experimental data from measurements on multiple sites have been used, with the same types of works. In fact the two scenarios presents similar works.

The number of persons exposed was estimated for both scenarios considering the average values of population densities (number of inhabitants per $\mathrm{km}^{2}$ ), in a metropolitan and in a peripheral area and the surface area of the excavation work site.

Finally, it has been adopted the same procedure of the health risk in the case without the working site, in order to define the additional impact on the population in the same area.

The WHO methodology was applied on the 2 scenarios, using data from airborne particulate matter concentration detected during an observation period of 20 months. Just the most significant 8 consecutive months has been taken into account, for data processing.

The area is $135000 \mathrm{~m}^{2}$ for both scenarios. The number of people exposed in Scenario A is 900, considering 6900 inhabitants per $\mathrm{km}^{2}$, while the 
suburban area of Scenario B presents 700 inhabitants per $\mathrm{km}^{2}$, with 90 people exposed.

\section{RESULTS}

\subsection{Scenario A}

The territory involved by the excavation work site has a high sensitivity to air pollution phenomena, since it is located in an urban area with a high population density. It is therefore important the contribution of vehicular traffic and domestic heating, which add up the emissions of the excavation work.

There are 20 events where there has been a daily average concentration on three consecutive days greater than 50 and $100 \mu \mathrm{g} \mathrm{m}^{-3}$ in the period of analysis.

The average daily range of $\mathrm{PM}_{10}$ concentrations on three consecutive days is $52 \mu \mathrm{g} \mathrm{m}^{-3}$ in March up to 195 $\mu \mathrm{g} \mathrm{m}^{-3}$ in February. Using the methodology of WHO, there were no cases of deaths and hospital admissions for respiratory problems among the population.

Interesting data regarding persons who may need a bronchodilator, or experience symptoms of respiratory irritation has been verified. It is reasonable to think that the most affected individuals belong to vulnerable groups.

Children who already suffer from respiratory problems (such as asthma and bronchitis), the elderly and those affected by respiratory and cardiovascular disease are particularly exposed to negative $\mathrm{PM}_{10}$ effects.

\subsection{Scenario B}

The average daily $\mathrm{PM}_{10}$ concentrations are very low, therefore there were no episodes of three or more consecutive days with values above 50 or $100 \mu \mathrm{g} \mathrm{m}^{-3}$. The analysis procedure shows that there is no significant health effects due to $\mathrm{PM}_{10}$ concentrations. It is evident, however, from the monitoring data, that there is an increase of concentration of $\mathrm{PM}_{10}$ of $10 \mu \mathrm{g} \mathrm{m} \mathrm{m}^{-3}$, therefore, in accordance with the WHO estimates of relative risk for short-term exposure, there is a quantifiable risk.

The health risk assessment has also been applied without the excavation work site, considering daily $\mathrm{PM}_{10}$ concentrations recorded by monitoring stations located in the metropolis. It is important to say that in case of ex ante evaluations, such average data are available in the Annual Air Quality Evaluations, produced by government agencies for the environment.

The number of total events where there has been a daily average concentration on three consecutive days greater than 50 and $100 \mu \mathrm{g} \mathrm{m}^{-3}$ in the period of analysis, without the excavation work site, is equal to 13, using the same criteria than the previous case.
The average daily range of $\mathrm{PM}_{10}$ concentrations on three consecutive days is $65 \mu \mathrm{g} \mathrm{m}^{-3}$ in October up to 63 $\mu \mathrm{g} \mathrm{m}^{-3}$ in February.

Monitoring data of scenario a show that the source of the excavation work, when placed in an urban area, is added to already high urban $\mathrm{PM}_{10}$ concentrations, considering the different weather conditions and the existing and induced source of traffic.

The total number of events with an average daily concentration of $\mathrm{PM}_{10}$ greater than or equal to $50 \mu \mathrm{g} \mathrm{m}^{-3}$ for three consecutive days (Fig. 1), empathizes the role of the excavation work activities in $\mathrm{PM}_{10}$ air pollution.

Focusing on this analysis there are two anomalies in December and February, where the number of events with an average daily concentration of $\mathrm{PM}_{10}$ greater than or equal to $50 \mu \mathrm{g} \mathrm{m}^{-3}$ for three consecutive days with the excavation work site is lower than the events without the excavation work site.

It is also necessary to analyze the trend of events during the month with a daily average concentration greater than or equal to $100 \mu \mathrm{g} \mathrm{m}^{-3}$ for three consecutive days (Fig. 2). In fact it can be noted that in December and February the number of episodes with this concentration is higher in the situation with the excavation work site. This underline the important impact on the population of the excavation work site in the metropolitan area. The analysis is therefore correct if it is taken into account both values of $\mathrm{PM}_{10}$ concentrations.

The most critical months are December and February, where the number of events is quite high (10 events.) The presence of the excavation work site leads to a worsening of an already serious situation. In fact, without the excavation work site, daily $\mathrm{PM}_{10}$ concentrations in these months are very high, probably due to an intensification of vehicular traffic and the use of domestic heating. The excavation work site provides to increase the events with concentrations above $100 \mu \mathrm{g} \mathrm{m}^{-3}$. In the month of August and March, moreover, without the excavation work site, there are no episodes with daily average concentrations for three consecutive days above 50 or $100 \mu \mathrm{g} \mathrm{m}^{-3}$. For instance, in presence of the excavation work site there is one event in August (with a concentration greater than 50 $\mu \mathrm{g} \mathrm{m}^{-3}$ ) and six events in March (with a concentration greater than $50 \mu \mathrm{g} \mathrm{m}^{-3}$ ).

The total number of events with an average daily concentration of $\mathrm{PM}_{10}$ over 50 or $100 \mu \mathrm{g} \mathrm{m}^{-3}$ for three consecutive days is greater when the excavation work site insists in the metropolitan area. In fact, according to the experimental data, between the condition with the excavation work site and the one without the excavation work site there is a difference of 13 episodes, which indicates an increase of $37 \%$ of the total number of events, when the excavation work site operates in the urban area. 
Giuseppe Pizzo and Marina Clerico / American Journal of Environmental Science 8 (4) (2012) 466-472

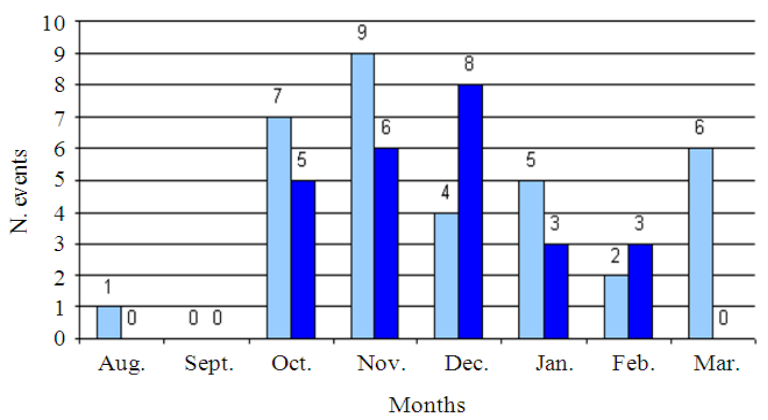

$\square$ No. events with concentration greater than $50 \mu \mathrm{g} \mathrm{m}^{-3}$ with excavation work site

- No. events with concentration greater than $50 \mu \mathrm{g} \mathrm{m} \mathrm{m}^{-3}$ without excavation work site

Fig. 1. Number of events with a $\mathrm{PM}_{10}$ concentration greater than or equal to $50 \mu \mathrm{g} \mathrm{m}^{-3}$ for three consecutive days

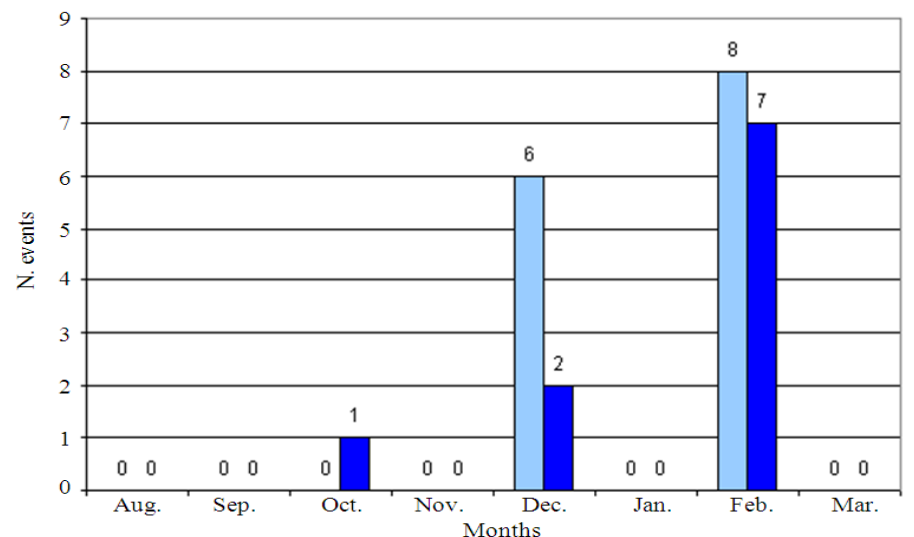

$\square \mathrm{N}$. events with concentration greater than $100 \mu \mathrm{g} \mathrm{m} \mathrm{m}^{-3}$ with excavation work site

- N. events with concentration greater than $100 \mu \mathrm{g} \mathrm{m} \mathrm{m}^{-3}$ without excavation work site

Fig. 2. Number of events with a $\mathrm{PM}_{10}$ concentration greater than or equal to $100 \mu \mathrm{g} \mathrm{m}^{-3}$ for three consecutive days

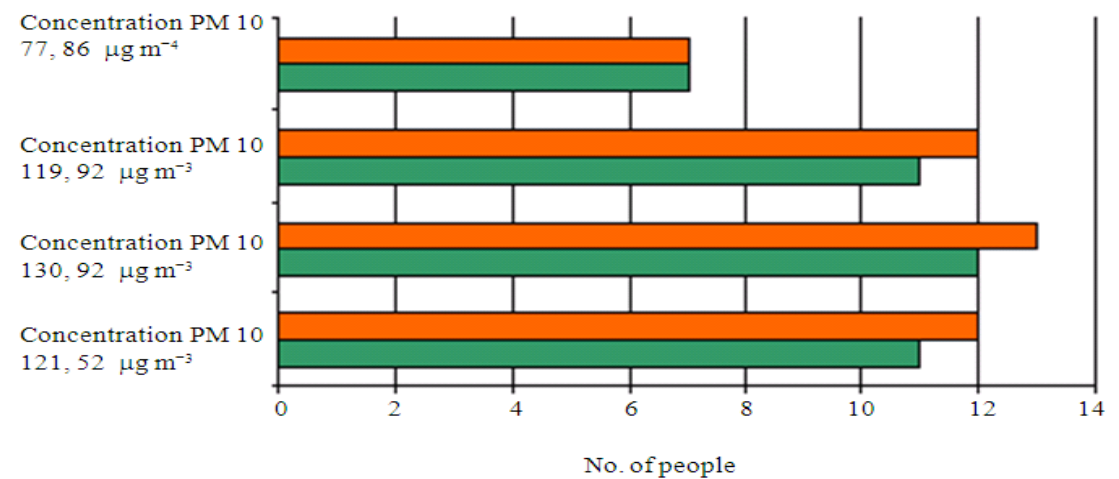

$\square$ No. of people who may experience respiratory irritation

$\square$ No. of people who may need a bronchodilator

Fig. 3. Health risk in December with the excavation work site 


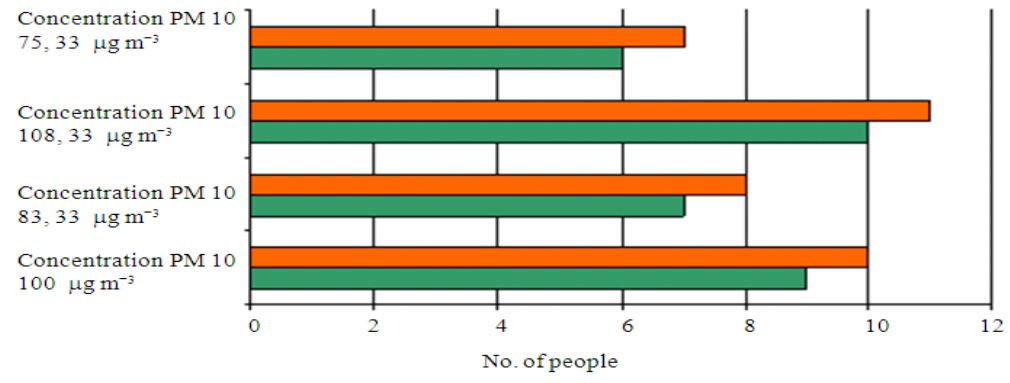

$\square$ No. of people who may experience respiratory irritation

$\square$ No. of people who may need a bronchodilator

Fig. 4. Health risk in December without the excavation work site

It is true that when the excavation work site is in urban peripheral area, there is no concentration of $\mathrm{PM}_{10}$ over 50 or $100 \mu \mathrm{g} \mathrm{m}^{-3}$ for three consecutive days, but there is an increase of PM concentration of $10 \mu \mathrm{g} \mathrm{m}^{-3}$, with corresponding health risk effect for the population.

This underlines that the site represents a significant source of particulate matter, contributing to the total exposure to $\mathrm{PM}_{10}$, even when the limit of $50 \mu \mathrm{g} \mathrm{m}^{-3}$ is not exceeded.

Figure 3 shows an example of health risk during the excavation work site activity.

The analysis of health risk shows a constant trend during the months of the two indicators "Number of people who may experience respiratory irritation" and "Number of people who may need a bronchodilator". This means that for the same $\mathrm{PM}_{10}$ concentration on three consecutive days, the number of people who may experience respiratory irritation is equal to the number of those who may need a bronchodilator.

There is in fact, among the two health conditions, a relationship: individuals who have respiratory problems such as asthma, bronchitis, pulmonary disease, almost certainly will need to use medicines containing bronchodilators. The difference between the two health situations may vary from a minimum of 1 to a maximum of 2 cases among those who will have problems of irritation. For daily average concentrations of $\mathrm{PM}_{10}$ on three consecutive days between 50 and $100 \mathrm{\mu g} \mathrm{m}^{-3}$, the number of persons who may experience adverse health effects is identical. If the concentration of $\mathrm{PM}_{10}$ exceeds $100 \mu \mathrm{g} \mathrm{m}^{-3}$, however, there is a deviation between the two effects. In fact, the higher the amount of $\mathrm{PM}_{10}$, the greater the difference between the number of those who may need bronchodilators and those who may experience respiratory irritation. It was found that there are cases of people suffering from possible adverse health effects even without the excavation work site (Fig. 4). The numbers reported, however, are lower than the condition with the excavation work site. This is a further indication of the impacting role of the excavation work site, resulting in an increasing of health risk for people living in the metropolitan area.

\section{DISCUSSION}

An excavation work site in urban area contribute to increase already significant background $\mathrm{PM}_{10}$ concentration values.

The high $\mathrm{PM}_{10}$ values already present in the urban area are in fact justified by the significant contribution of road traffic, which represents more than $60 \%$ of the emission sources.

During the monitoring period, the only urban area under study, without the excavation work site, were recorded from 118 to 151 exceedances of daily limit of 50 $\mu \mathrm{m} \mathrm{m}_{-3}^{-3}$, while the annual average exceeds the limit of 40 $\mu \mathrm{m} \mathrm{m}^{-3}$, recording values ranging from 50 to $57 \mu \mathrm{m} \mathrm{m}^{-3}$.

This is shown by the results obtained from the application of WHO guidelines in the excavation work sites for $\mathrm{PM}_{10}$ pollution episodes for three consecutive days.

WHO points out, however, that the available epidemiological data, on which the guidelines are based, does not allow defining a threshold concentration for these risk factors. In addition, short-term effects on human health have been associated with short-term exposure below the $100 \mu \mathrm{g} \mathrm{m}^{-3}$ daily average concentration of $\mathrm{PM}_{10}$, while long-term effects were also observed in annual average concentrations below 20 for $\mathrm{PM}_{2,5}$ and 30 $\mu \mathrm{g} \mathrm{m}^{-3}$ for $\mathrm{PM}_{10}$. Such uncertainty cannot therefore set a standard for PM with an adequate margin of safety.

It is proposed by $\mathrm{WHO}$, for the purposes of risk management, to refer to risk estimation, as defined above, in place of a guideline value. The EU has instead provided specific exposure limits for PM concentration, based on safety of the population exposed. Such exposure limits are therefore adopted in Italy to conform to EU standards.

It should be underlined, however, that excavation work sites are often extended in time and can exceed the legal limits set by the EU for the annual average of PM. 
In this case it would be necessary to consider the excavation work site as an establishment and therefore to ask the authorization for the emissions, in accordance with Directive $84 / 360 /$ EEC on the combating of air pollution from industrial plants.

\section{CONCLUSION}

The numerical values set by the WHO Air Quality Guidelines represent concentrations with specific responses caused by exposure to particulate matter. However there is an inter-individual variability in exposure and is still unlikely that any standard or guideline value for airborne particulates will provide universal protection against possible adverse effects of PM for each individual.

The WHO $\mathrm{PM}_{10}$ health risk estimates were applied to the excavation work site, considering the above guidelines as precautionary measures. They appeared indeed to be proportionate to the desired level of protection, comparable to similar situations and different in different situations, consistent and ultimately subject to revision according to new scientific data.

In this research study, the risk assessment represents a precautionary approach, which has become one of the central concepts for the prevention of environmental risks at an international level. The comparison between the situation in the presence of the excavation work site and without the excavation work site has allowed highlighting the important role of the it, thus providing further evidence to the scientific problem of the emission of dust into the atmosphere, related to excavation activities. Indeed, where the values of background, in the absence of the excavation work site, exceeded the limits of legislation, the excavation work site represented a critical factor for the increasing of the health risk factors. This risk is also present in the case where the absolute limit values are not exceeded, because the increase of $\mathrm{PM}_{10}$ concentration due to the excavation activities, can provide a quantifiable risk.

This research work tried therefore to move from a situation of known impacts and unknown probabilities to a known impacts and known probabilities.

The quantitative risk assessment provides an approach for comparing alternative scenarios and to estimate the residual risk when a possible guidance value is achieved. The epidemiological data do not permit to define a threshold concentration for these risk factors and is therefore not possible to establish a standard for PM with an adequate margin of safety. The results of this study should therefore provide a basis for discussion to stimulate debate and decisions of public authorities, in order to deepen and to address issues related to particulate matter.

Scientific research could also be oriented towards the monitoring of the fraction $\mathrm{PM}_{2,5}$ in the excavation work site, to determine the annual average concentration.
Consequently, it would be possible to estimate and evaluate the health risk for the population near the excavation work site, studying the exposure during an entire year with annual average concentrations of $\mathrm{PM}_{2,5}$ higher than the value of background, adopting WHO estimates of health risk for long-term exposure.

\section{REFERENCES}

ATS, 2000. What constitutes an adverse health effect of air pollution? Am. J. Respiratory Crit. Care Med., 161: 665-673.

Zagar, T., P. Otorepec and M. Gregoric, Apheis, 2005. Health Impact Assessment of Air Pollution and Communication Strategy. 1st Edn., Institut de Veille Sanitaire, Cedex, ISBN-10: 2110948388, pp: 200.

CEPMEIP, 003. Co-ordinated european programme on particulate matter emission.

Dockery, D.W., C.A. Pope, X. Xu, J.D. Spengler and J.H. Ware et al., 1993. An association between air pollution and mortality in Six U.S. Cities. New Eng. J. Med., 329: 1753-1759. DOI: 10.1056/NEJM199312093292401

Dockery, D.W., J. Cunningham, A.I. Damokosh, L.M. Neas and J.D. Spengler et al., 1996. Health effects of acid aerosols on North American children: Respiratory symptoms. Environ. Health Perspect., 104: 500-505. PMID: 8743437

EEA, 2007. Air pollution in Europe 1990-2004, Copenhagen. European Environment Agency.

EEA, 2009. EMEP/EEA air pollutant emission inventory guidebook. European Environment Agency.

Larsen, B., 2008. Source Apportionment of $\mathrm{PM}_{10}$ by chemical analysis and receptor modelling: Krakow, Poland (coal combustion), Po Valley.

Pizzo, G. and M. Clerico, 2011. Particulate matter in the excavation work sites in urban areas. Am. J. Environ. Sci., 7: 499-504. DOI: 10.3844/ajessp.2011.499.504

Pope, C.A., R.T. Burnett, M.J. Thun, E.E. Calle and D. Krewski et al., 2002. Lung cancer, cardiopulmonary mortality and long-term exposure to fine particulate air pollution. J. Am. Med. Assoc., 287: 1132-1141. PMID: 11879110

Pope, C.A., M.J. Thun, M.M. Namboodiri, D.W. Dockery and J.S. Evans, 1995. Particulate air pollution as a predictor of mortality in a prospective study of U.S. adults. Am. J. Respiratory Critical Care Med., 151: 669-674. PMID: 7881654

WHO, 2003. Health Aspects of Air Pollution with Particulate Matter, Ozone and Nitrogen Dioxide. WHO Regional Office for Europe, 2003.

WHO, 2006. Air Quality Guidelines: Global Update 2005: Particulate Matter, Ozone, Nitrogen Dioxide and Sulfur Dioxide. 1st Edn., World Health Organization, Denmark, ISBN-10: 9289021926, pp: 484.

Zhang, K., S. Betterman and F. Dion, 2011. Vehicle emissions in congestion: Comparison of work zone, rush hour and free-flow conditions. Atmospheric Environ., 45: 1929-1939. 